\title{
Icotinib and pemetrexed in treatment of lung adenocarcinoma and the effects on prognostic survival rate of patients
}

\author{
XUEHENG ZHOU ${ }^{1}$, DEFENG HUA ${ }^{2}$, CHENGPENG GAO ${ }^{3}$, \\ YIXIANG ZHANG ${ }^{3}$, LIJIE QIU ${ }^{3}$ and LEQIANG WANG ${ }^{3}$ \\ ${ }^{1}$ Department of Pharmacy, Affiliated Hospital of Weifang Medical University, Weifang, Shandong 261031; \\ ${ }^{2}$ Department of Neurology, Weifang Brain Hospital, Weifang, Shandong 261000; \\ ${ }^{3}$ Department of Respiratory Medicine, Weifang People's Hospital, \\ Weifang, Shandong 261041, P.R. China
}

Received September 24, 2018; Accepted May 1, 2019

DOI: $10.3892 / 01.2019 .10763$

\begin{abstract}
Efficacy comparison of icotinib and pemetrexed in the treatment of lung adenocarcinoma and the effects on the prognostic survival rate of patients were investigated. A retrospective analysis was performed in 132 lung adenocarcinoma patients who were treated in the Affiliated Hospital of Weifang Medical University from July 2010 to July 2015. Among them, 69 patients were treated with icotinib (icotinib group), and 63 patients were treated with pemetrexed (pemetrexed group). In the icotinib group, $125 \mathrm{mg}$ icotinib was orally administered continuously, 3 times a day, until progressive disease or intolerable adverse reactions occurred. In the pemetrexed group, $500 \mathrm{mg} / \mathrm{m}^{2}$ pemetrexed was intravenously dripped for a total of 4 cycles, 21 days for 1 cycle, until progressive disease or intolerable adverse reactions occurred. The efficacy, toxic and side effects, and survival rate of the two groups were evaluated. There was a statistically significant difference in toxic and side effects between the two groups of drugs after the treatment of lung adenocarcinoma $(\mathrm{P}<0.05)$. The median survival time of patients was 16 months in the icotinib group and 10 months in the pemetrexed group, with a statistically significant difference $(\mathrm{P}<0.05)$. The 1 -year survival rate was higher in the icotinib group than that in the pemetrexed group $(\mathrm{P}<0.05)$. There was no difference in 2- and 3-year survival rates between the two groups $(\mathrm{P}>0.05)$. In conclusion, the clinical efficacy of icotinib is similar to that of pemetrexed in the treatment of lung adenocarcinoma, but icotinib has less adverse reactions, with better improvement in disease control.
\end{abstract}

Correspondence to: Dr Leqiang Wang, Department of Respiratory Medicine, Weifang People's Hospital, 151 Guangwen Street, Weifang, Shandong 261041, P.R. China

E-mail: ehw9qt@163.com; wangleqiang5308@sina.com

Key words: icotinib, pemetrexed, lung adenocarcinoma, efficacy, prognostic survival rate

\section{Introduction}

The number of smokers is increasing with the increase of modern life pressure (1). In daily social life, people are forced to absorb second-hand smoke from people around them, and studies have shown that the risk of being forced to absorb second-hand smoke is much higher than that of normal smoking (2). Lung cancer has the highest mortality and morbidity rates worldwide (3). Patients with non-small cell lung cancer (NSCLC) account for $>80 \%$ of the total number of lung cancer patients (4), and lung adenocarcinoma is the most common in NSCLC (5). Lung adenocarcinoma has a high degree of malignancy, short survival time and high mortality (6). Due to the mild early symptoms that are difficult to detect, most lung adenocarcinoma patients have entered advanced stage when diagnosed (7). Clinically, chemotherapy is still the preferred treatment regimen for patients with advanced malignant tumors (8). However, patients with malignant tumors, generally have reduced immune function, with many adverse reactions to chemotherapeutics, and often have limited tolerance and efficacy to the drugs (9).

As a receptor tyrosinase inhibitor against epidermal growth factor, icotinib has high specificity for tyrosine kinase on epidermal growth factor (10), which prolongs the survival time of lung adenocarcinoma patients, but drug resistance is prone to occur with prolonged treatment time (11). Pemetrexed, a newly developed anti-folate agent with multiple targets and few toxic and side effects, can effectively inhibit tumor cell proliferation (12). At present, chemotherapeutics in combination with platinum drugs is an often used standard first-line chemotherapy regimen (13). Some studies have shown that the efficacy of pemetrexed in combination with platinum drugs is better, which can improve adverse reactions of drugs and clinical efficacy, prolonging patients' survival time (14). In this study, the clinical efficacy of icotinib and pemetrexed in combination with cisplatin in the first-line treatment of lung adenocarcinoma was compared, and the correlation of different treatment regimens with the prognosis and survival of patients was evaluated. 


\section{Patients and methods}

Experimental subjects. A retrospective analysis was performed in 132 lung adenocarcinoma patients who were treated in the Affiliated Hospital of Weifang Medical University (Weifang, China) from July 2010 to July 2015. Among them, 69 patients were treated with icotinib as the icotinib group, including 45 males and 24 females, aged 35-71 years, with an average age of $(54.32 \pm 6.46)$ years. The other 63 patients were treated with pemetrexed as the pemetrexed group, including 42 males and 21 females, aged 36-67 years, with an average age of $(53.85 \pm 6.83)$ years.

Inclusion criteria were: i) Lung adenocarcinoma patients (with stages IIIA, IIIB and IV) diagnosed by the pathology department of the Affiliated Hospital of Weifang Medical University and unable or unwilling to undergo operation, or recurrent patients 6 months after operation and radiotherapy and chemotherapy; ii) patients with US Eastern Cancer Cooperative Group (ECOG) score $(15) \leq 1$ point and initial expected survival time $>3$ months; iii) patients with observable tumor lesion $\geq 1$, and iv) The amplification refractory mutation system (ARMS) kit was used to detect EGFR genic mutations at exon 18 , exon 19 or exon 21.

Exclusion criteria were: i) Patients with systemic immune system diseases or extremely low immune ability who were intolerant to chemotherapy; ii) patients with severe heart insufficiency or liver and kidney dysfunction, and iii) patients allergic to drugs used in this experiment.

The study was approved by the Ethics Committee of the Affiliated Hospital of Weifang Medical University. Signed informed consents were obtained from the patients or the guardians.

Experimental reagents and instruments. Icotinib hydrochloride (Beida Pharmaceutical Co., Ltd., H20110060), pemetrexed disodium for injection (Shanghai Kaimao Biomedical Co., Ltd., H20123010), cisplatin (Jinzhou Jiutai Pharmaceutical Co., Ltd., H21020751) and folic acid tablet (Hangzhou Australian Medical Baoling Pharmaceutical Co., Ltd., H20123159). ARMS kit was purchased from MSK Biotechnology Co., Ltd.

Experimental methods. All patients were given routine treatment such as anti-emesis, stomach protection and fluid infusion on the first 3 days of chemotherapy. Patients in the pemetrexed group were additionally orally administered 1 folic acid tablet $(0.4 \mathrm{mg} /$ tablet $)$ daily for 3 weeks from the first 7 days of chemotherapy to the last administration of chemotherapy for enhancing the efficacy. The drug regimen of patients in the icotinib group was: icotinib $125 \mathrm{mg} / \mathrm{time}$, 3 times/day orally, days 1-28. The drug regimen of patients in the pemetrexed group was: pemetrexed $500 \mathrm{mg} / \mathrm{m}^{2}$, day 1 , intravenous drip; cisplatin, $25 \mathrm{mg} / \mathrm{m}^{2}$, days $1-3$. Patients in the icotinib group were not given medicine during continuous drug use if progressive tumor or intolerable toxic and side effects occurred. The first evaluation of patients was performed 4 weeks after the last administration, and then evaluation was performed once every six weeks. A total of 21 days for 1 chemotherapy cycle, patients in the pemetrexed group were continuously administered for 4 cycles. After each two chemotherapy cycles, patient was reviewed to evaluate the efficacy of drugs. If progressive tumor or severe adverse reactions occurred, medication was stopped.

Evaluation criteria for efficacy as well as toxic and side effects (16). Patients with different medications in the two groups were observed and their conditions after medication were recorded. The efficacy of drugs was evaluated based on the Response Evaluation Criteria in Solid Tumors (RECIST), divided into: complete response (CR): all target lesions of patients disappeared for $>28$ consecutive days; partial response (PR): the total diameter of the target lesion of patients reduced by $30 \%$, maintaining for $>28$ days; stable disease (SD): the total diameter of the target lesion of patients increased by $\leq 20 \%$, or reduced $\leq 30 \%$; progressive disease (PD): the total diameter of the target lesion of patients increased by $\geq 20 \%$, or new target lesions appeared. The observation indicator was progression-free survival time when progressive tumor or death occurred in patients. Overall response rate $(\mathrm{ORR})=(\mathrm{CR}+\mathrm{PR}) /$ total number $\mathrm{x} 100 \%$. Disease control rate $(\mathrm{DCR})=(\mathrm{CR}+\mathrm{PR}+\mathrm{SD}) /$ total number $\mathrm{x} 100 \%$. The toxic and side effects of drugs were evaluated based on the National Cancer Institute General Toxicity Standard (NCI-CTC.4.0) (17).

Statistical analysis. SPSS 19.0 statistical software (SPSS Inc.) was used for statistical analysis of the experimental data. Enumeration data were expressed as $\%$, and Chi-square $\left(\chi^{2}\right)$ test was used for comparison between the groups and pairwise comparisons were made followed by Bonferroni post hoc test. $\chi^{2}$ test was used when the total number of cases was $n \geq 40$ and all theoretical frequencies $\mathrm{T} \geq 5$. Fisher's exact test was used when $n \geq 40$, but $\geq 1 \mathrm{~T}<5$. Measurement data were expressed as mean $\pm \mathrm{SD}$, and t-test was used for comparison between the groups. Kaplan-Meier test was used for survival analysis. The log-rank test was used to compare the survival distribution between the two samples. At $\mathrm{P}<0.05$, the difference was considered statistically significant.

\section{Results}

Comparison of clinical basic data. As shown in Table I, there were no differences in age, body mass index and blood pressure between the icotinib and pemetrexed groups of patients $(\mathrm{P}>0.05)$.

Comparison of clinical efficacy. The clinical efficacy was evaluated in the two groups of patients. Patients in the icotinib group were treated for $>28$ days, and patients in the pemetrexed group for at least 2 cycles. There was no treatment-related death in the two groups. ORR was $34.78 \%$ in the icotinib group and $28.57 \%$ in the pemetrexed group, and DCR was $75.36 \%$ in the icotinib group and $69.84 \%$ in the pemetrexed group, with no statistically significant differences $(\mathrm{P}>0.05)$ (Table II).

Comparison of toxic and side effects. The main toxic and side effects of icotinib were rash (39.13\%), constipation or diarrhea $(20.29 \%)$, hepatotoxicity $(17.39 \%)$ and nausea and vomiting (13.04\%), with generally less toxic and side effects at grades III-IV (Table III). Those of pemetrexed 
Table I. Comparison of clinical basic data (mean \pm SD) [n (\%)].

\begin{tabular}{|c|c|c|c|c|}
\hline Clinical features & Icotinib group $(n=69)$ & Pemetrexed group $(n=63)$ & $\mathrm{t} / \chi^{2}$ & P-value \\
\hline Age (years) & $54.32 \pm 6.46$ & $53.85 \pm 6.83$ & 0.406 & 0.685 \\
\hline Body mass index $\left(\mathrm{kg} / \mathrm{m}^{2}\right)$ & $20.63 \pm 2.58$ & $21.22 \pm 2.41$ & 1.354 & 0.178 \\
\hline Systolic pressure (mmHg) & $126.47 \pm 12.39$ & $128.38 \pm 8.25$ & 1.032 & 0.304 \\
\hline Diastolic pressure (mmHg) & $74.53 \pm 3.58$ & $73.68 \pm 5.39$ & 1.076 & 0.284 \\
\hline Sex & 0.031 & 0.861 & & \\
\hline Male & $45(65.22)$ & $42(66.67)$ & & \\
\hline Female & $24(24.78)$ & $21(33.33)$ & & \\
\hline Clinical stages & 0.049 & 0.976 & & \\
\hline IIIA & $2(2.90)$ & $2(3.17)$ & 0.009 & 0.926 \\
\hline IIIB & $5(7.25)$ & $4(6.35)$ & 0.042 & 0.838 \\
\hline IV & $62(89.85)$ & $57(90.48)$ & 0.014 & 0.905 \\
\hline Performance status & 0.128 & 0.938 & & \\
\hline 0 & $3(4.35)$ & $2(3.17)$ & 0.124 & 0.724 \\
\hline 1 & $65(94.20)$ & $60(95.24)$ & 1.513 & 0.219 \\
\hline 2 & $1(1.45)$ & $1(1.59)$ & 0.004 & 0.948 \\
\hline
\end{tabular}

Table II. Comparison of clinical efficacy between icotinib and pemetrexed in treatment of lung adenocarcinoma.

\begin{tabular}{|c|c|c|c|c|c|c|}
\hline Groups & $\begin{array}{l}\mathrm{CR} \text { (complete } \\
\text { remission) }\end{array}$ & $\begin{array}{l}\text { PR (partial } \\
\text { remission) }\end{array}$ & $\begin{array}{l}\text { SD (stable } \\
\text { disease) }\end{array}$ & $\begin{array}{c}\text { PD (progressive } \\
\text { disease) }\end{array}$ & $\begin{array}{l}\text { ORR (overall } \\
\text { response rate) }\end{array}$ & $\begin{array}{c}\text { DCR (disease } \\
\text { control rate) }\end{array}$ \\
\hline Icotinib group $(n=69)$ & $2(2.90)$ & $22(31.88)$ & $28(40.58)$ & $17(24.64)$ & $24(34.78)$ & $52(75.36)$ \\
\hline Pemetrexed group $(n=63)$ & $1(1.59)$ & $17(26.98)$ & $26(41.27)$ & $19(30.16)$ & $18(28.57)$ & $44(69.84)$ \\
\hline$\chi^{2}$ & 0.006 & 0.380 & 0.006 & 0.506 & 0.586 & 0.506 \\
\hline P-value & 0.937 & 0.048 & 0.936 & 0.477 & 0.444 & 0.477 \\
\hline
\end{tabular}

Table III. Toxic side effects of icotinib in treatment of lung adenocarcinoma [n (\%)].

\begin{tabular}{|c|c|c|c|c|c|}
\hline \multirow[b]{2}{*}{ Toxic and side effects } & \multicolumn{5}{|c|}{ Icotinib group $(n=69)$} \\
\hline & $\mathrm{I}$ & II & III & IV & Total number of cases \\
\hline Leukopenia & $4 \quad(5.80)$ & $2(2.90)$ & $2(2.90)$ & $0(0.00)$ & $8(11.59)$ \\
\hline Neutropenia & $2(2.90)$ & $1(1.45)$ & $1(1.45)$ & $0(0.00)$ & $4 \quad(5.80)$ \\
\hline Thrombocytopenia & $3(4.35)$ & $2(2.90)$ & $0(0.00)$ & $0(0.00)$ & $5 \quad(7.25)$ \\
\hline Anemia & $2(2.90)$ & $1(1.45)$ & $0(0.00)$ & $0(0.00)$ & $3(4.35)$ \\
\hline Nausea and vomiting & $6 \quad(8.70)$ & $2(2.90)$ & $1(1.45)$ & $0(0.00)$ & $9(13.04)$ \\
\hline Constipation or diarrhea & $8(11.59)$ & $3(4.35)$ & $2(2.90)$ & $1(1.45)$ & $14(20.29)$ \\
\hline Rash & $24(34.78)$ & $3(4.35)$ & $0(0.00)$ & $0(0.00)$ & $27(39.13)$ \\
\hline Alopecia & $2(2.90)$ & $1(1.45)$ & $0(0.00)$ & $0(0.00)$ & $3(4.35)$ \\
\hline Fatigue & $7(10.14)$ & $3(4.35)$ & $0(0.00)$ & $0(0.00)$ & $7(10.14)$ \\
\hline Peripheral nerve toxicity & $1 \quad(1.45)$ & $5(7.25)$ & $0(0.00)$ & $0(0.00)$ & $6 \quad(8.70)$ \\
\hline Stomatitis & $3(4.35)$ & $2(2.90)$ & $0(0.00)$ & $0(0.00)$ & $5 \quad(7.25)$ \\
\hline Hepatotoxicity & $8(11.59)$ & $3(4.35)$ & $1(1.45)$ & $0(0.00)$ & $12(17.39)$ \\
\hline Neurotoxicity & $1 \quad(1.45)$ & $0(0.00)$ & $0(0.00)$ & $0(0.00)$ & $1 \quad(1.45)$ \\
\hline
\end{tabular}

were leukopenia $(47.62 \%)$, neutropenia $(63.49 \%)$, thrombocytopenia $(36.51 \%)$, nausea and vomiting $(73.02 \%)$, fatigue $(55.56 \%)$ and peripheral nerve toxicity $(34.92 \%$ (Table IV).
The toxic and side effects of the two groups were compared by $\chi^{2}$ test. The incidence of leukopenia, neutropenia, thrombocytopenia, anemia, nausea and vomiting, fatigue and peripheral 
Table IV. Toxic side effects of pemetrexed in the treatment of lung adenocarcinoma [n (\%)].

\begin{tabular}{|c|c|c|c|c|c|}
\hline \multirow[b]{2}{*}{ Toxic and side effects } & \multicolumn{5}{|c|}{ Pemetrexed group $(n=63)$} \\
\hline & I & II & III & IV & Total number of cases \\
\hline Leukopenia & $12(19.05)$ & $9(14.29)$ & $8(12.70)$ & $1(1.59)$ & $30(47.62)$ \\
\hline Neutropenia & $18(28.57)$ & $10(15.87)$ & $8(12.70)$ & $4(6.35)$ & $40(63.49)$ \\
\hline Thrombocytopenia & $12(19.05)$ & $6 \quad(9.52)$ & $5 \quad(7.94)$ & $0(0.00)$ & $23(36.51)$ \\
\hline Anemia & $8(12.70)$ & $4(6.35)$ & $3(4.76)$ & $0(0.00)$ & $15(23.81)$ \\
\hline Nausea and vomiting & $27(42.86)$ & $16(25.40)$ & $3(4.76)$ & $0(0.00)$ & $46(73.02)$ \\
\hline Constipation or diarrhea & $11(17.46)$ & $3(4.76)$ & $1(1.59)$ & $0(0.00)$ & $15(23.81)$ \\
\hline Rash & $3(4.76)$ & $2(3.17)$ & $0 \quad(0.00)$ & $0(0.00)$ & $5(7.94)$ \\
\hline Alopecia & $4(6.35)$ & $1(1.59)$ & $0 \quad(0.00)$ & $0(0.00)$ & $5(7.94)$ \\
\hline Fatigue & $23(36.51)$ & $10(15.87)$ & $2(3.17)$ & $0(0.00)$ & $35(55.56)$ \\
\hline Peripheral nerve toxicity & $17(16.98)$ & $5 \quad(7.94)$ & $0 \quad(0.00)$ & $0(0.00)$ & $22(34.92)$ \\
\hline Stomatitis & $4 \quad(6.35)$ & $1 \quad(1.59)$ & $0 \quad(0.00)$ & $0(0.00)$ & $5 \quad(7.94)$ \\
\hline Hepatotoxicity & $8(12.70)$ & $3(4.76)$ & $2(3.17)$ & $0(0.00)$ & $13(20.63)$ \\
\hline Neurotoxicity & $1(1.59)$ & $0 \quad(0.00)$ & $0 \quad(0.00)$ & $0(0.00)$ & $1(1.59)$ \\
\hline
\end{tabular}

Table V. Comparison of toxic and side effects between icotinib and pemetrexed in the treatment of lung adenocarcinoma [n (\%)].

\begin{tabular}{lccrr}
\hline & \multicolumn{4}{c}{ Total number of cases } \\
\cline { 2 - 5 } Toxic and side effects & Icotinib group $(\mathrm{n}=69)$ & Pemetrexed group $(\mathrm{n}=63)$ & $\chi^{2}$ & P-value \\
\hline Leukopenia & $8(11.59)$ & $30(47.62)^{\mathrm{a}}$ & 20.850 & $<0.001$ \\
Neutropenia & $4(5.80)$ & $40(63.49)^{\mathrm{a}}$ & 49.330 & $<0.001$ \\
Thrombocytopenia & $5(7.25)$ & $23(36.51)^{\mathrm{a}}$ & 16.870 & $<0.001$ \\
Anemia & $3(4.35)$ & $15(23.81)^{\mathrm{a}}$ & 10.590 & $<0.001$ \\
Nausea and vomiting & $9(13.04)$ & $46(73.02)^{\mathrm{a}}$ & 48.730 & $<0.001$ \\
Constipation or diarrhea & $14(20.29)$ & $15(23.81)$ & 0.238 & 0.626 \\
Rash & $27(39.13)$ & $5(7.94)^{\mathrm{a}}$ & 17.450 & $<0.001$ \\
Alopecia & $3(4.35)$ & $5(7.94)$ & 0.278 & 0.619 \\
Fatigue & $7(10.14)$ & $35(55.56)^{\mathrm{a}}$ & 31.300 & $<0.001$ \\
Peripheral nerve toxicity & $6(8.70)$ & $22(34.92)^{\mathrm{a}}$ & 13.550 & $<0.001$ \\
Stomatitis & $5(7.25)$ & $5(7.94)$ & 0.024 & 0.878 \\
Hepatotoxicity & $12(17.39)$ & $13(20.63)$ & 0.226 & 0.635 \\
Neurotoxicity & $1(1.45)$ & $1(1.59)$ & 0.420 & 0.517 \\
\hline
\end{tabular}

Fisher's test was used when the frequency was $\mathrm{T}<5$. ${ }^{\mathrm{a}} \mathrm{P}<0.05$, compared to the icotinib group.

nerve toxicity was higher in the pemetrexed group than that in the icotinib group, but that of rash was higher in the icotinib group than that in the pemetrexed group $(\mathrm{P}<0.05)$. The comparison of other toxic and side effects was not significant $(\mathrm{P}>0.05)$ (Table V).

Survival. Patients in the two groups were followed up until July 2018. The median survival time of patients was 16 months in the icotinib group, higher than that in the pemetrexed group (10 months), with a statistically significant difference $(\mathrm{P}<0.05)$. The 1 -year survival rate was higher in the icotinib group than that in the pemetrexed group $(\mathrm{P}<0.05)$. There were no differences in 2- and 3-year
Table VI. Comparison of survival rate between the icotinib and pemetrexed groups [n (\%)].

\begin{tabular}{llll}
\hline Case number/ratio & 1-year & 2-years & 3-years \\
\hline Icotinib group $(\mathrm{n}=69)$ & $44(63.77)$ & $23(33.33)$ & $9(13.04)$ \\
Pemetrexed group $(\mathrm{n}=63)$ & $29(46.03)$ & $17(26.98)$ & $7(11.11)$ \\
$\chi^{2}$ & 4.191 & 0.364 & 0.005 \\
P-value & 0.041 & 0.546 & 0.942 \\
\hline
\end{tabular}

survival rates between the two groups $(\mathrm{P}>0.05)$ (Table VI and survival curve in Fig. 1). 


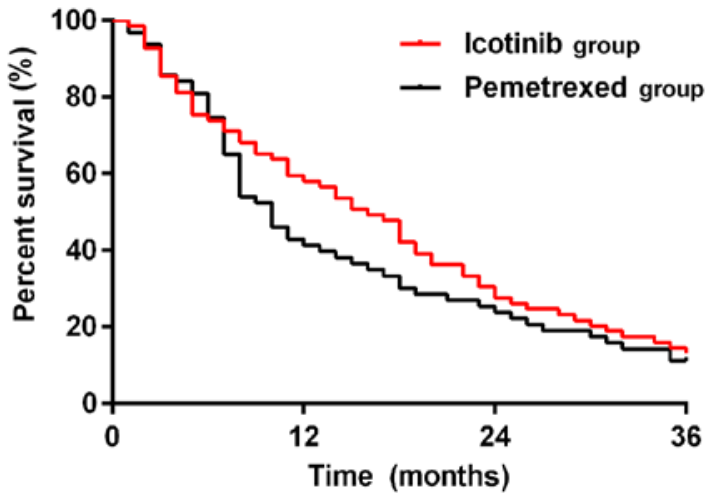

Figure 1. Comparison of survival rate between icotinib and pemetrexed in treatment of lung adenocarcinoma. The results of Kaplan-Meier test for survival analysis showed that the median survival time of patients was 16 months in the icotinib group, higher than that in the pemetrexed group (10 months), with a statistically significant difference $(\mathrm{P}<0.05)$. The 1 -year survival rate was higher in the icotinib group than that in the pemetrexed group $(\mathrm{P}<0.05)$. There were no differences in 2 - and 3 -year survival rates between the two groups $(\mathrm{P}>0.05)$.

\section{Discussion}

Lung cancer is a malignant tumor mostly occurring in the middle-aged and elderly (18). Most patients miss the best treatment time of operation because of untimely treatment, so its main clinical treatment is chemotherapy (19). Having various organ dysfunction with poor stress ability, middle-aged and elderly patients cannot well tolerate chemotherapeutics (20). Thus, more complications and lesion metastasis occur in them, seriously threatening their life and health (21). In order to prolong the survival time of patients, the most important point for the treatment of malignant tumors is to find chemotherapeutics with good efficacy and few adverse reactions.

Icotinib is a small molecule targeted anti-cancer drug independently developed in China, which is suitable for patients with middle and advanced NSCLC and easy to use, with fewer toxic and side effects (22). Currently, clinical studies have shown that pemetrexed can significantly prolong the survival time of adenocarcinoma patients and better control progressive disease (23). However, the incidence of its toxic and side effects such as myelosuppression (leukopenia, neutropenia and thrombocytopenia) and gastrointestinal reactions is high, therefore it is difficult to achieve the desired efficacy (24). Long-term pemetrexed combination treatment still has high requirements for patients' physical quality, but there are extremely few studies on the efficacy comparison between icotinib and pemetrexed in clinical practice. In this study, the efficacy, safety and survival rate were compared between the two groups of drugs to help the first-line treatment of lung adenocarcinoma.

The results of this study showed that the progression-free survival time of icotinib was significantly higher than that of pemetrexed in the treatment of lung adenocarcinoma $(\mathrm{P}<0.05)$. ORR was $34.78 \%$ in icotinib group and $28.57 \%$ in the pemetrexed group, and DCR was $75.36 \%$ in the icotinib group and $69.84 \%$ in the pemetrexed group, with no statistically significant differences $(\mathrm{P}>0.05)$. It is suggested that both drugs have good efficacy. The median survival time of patients was 16 months in the icotinib group, higher than 10 months in the pemetrexed group, with a statistically significant difference $(\mathrm{P}<0.05)$. The 1-year survival rate was higher in the icotinib group compared with that in the pemetrexed group $(\mathrm{P}<0.05)$. There were no differences in 2- and 3-year survival rates between the two groups $(\mathrm{P}>0.05)$. Gefitinib, the tyrosinase inhibitor of epidermal growth factor receptor (EGFR), which is currently the most commonly used in clinic, inhibits the invasion, infiltration, proliferation and angiogenesis of tumor cells (25). It can prolong the survival time of lung adenocarcinoma patients, especially the median and progression-free survival time, improving patients' quality of life (26). Studies have shown that icotinib, as a small molecule EGFR tyrosinase inhibitor independently developed in China, can be equivalent to gefitinib, which has been confirmed in clinical applications (27). Even for patients with EGFR mutations, icotinib can selectively inhibit the binding of ATP and EGFR tyrosine kinase to reduce the biological activity of EGFR-TKI, thereby inhibiting the proliferation, invasion and metastasis of cancer cells (28). Pemetrexed is a novel anti-folate drug that inhibits multiple enzyme targets depending on folate metabolism. It can enable tumor cells to synthesize pyrimidine and purine disorders, stopping tumor cell growth in $\mathrm{S}$ phase, so as to inhibit the growth and proliferation of tumor cells (29). Several studies have shown that pemetrexed tends to achieve better ORR and DCR than other first-line chemotherapeutics in the treatment of non-squamous cancer malignant tumors such as adenocarcinoma (30). Both icotinib and pemetrexed have good efficacy in lung adenocarcinoma. It may be considered clinically that icotinib combined with pemetrexed can be used to inhibit tumor growth and proliferation, prolonging the survival time of lung adenocarcinoma patients, to obtain better efficacy.

The main toxic and side effects of icotinib were rash $(39.13 \%)$, constipation or diarrhea $(20.29 \%)$, hepatotoxicity $(17.39 \%)$ and nausea and vomiting (13.04\%), with generally less toxic and side effects at grades III-IV. Those of pemetrexed were leukopenia (47.62\%), neutropenia (63.49\%), thrombocytopenia $(36.51 \%)$, nausea and vomiting $(73.02 \%)$, fatigue $(55.56 \%)$ and peripheral nerve toxicity (34.92\%). It is suggested that the incidence of toxic and side effects of pemetrexed is significantly higher than that of icotinib. Literature (31) shows that after a short-term withdrawal or symptomatic treatment, the toxic and side effects of icotinib, rash and diarrhea, can be alleviated to a great extent. Even for milder toxic and side effects at grades I-II, symptoms disappear on their own within a certain period of time (31). Therefore, lung adenocarcinoma patients with poor physical quality may have longer tolerance time to treatment with icotinib and higher quality of life.

However, in this study, there are also some limitations. First, the sample size of patients is still insufficient. When survival analysis was performed, the time span was not long enough. It is necessary to collect more cases for a long-term follow-up study. Second, the mechanism of action of icotinib and pemetrexed in lung adenocarcinoma tumor cells is still not clear enough. In this study, we did not compare icotinib with other drugs such as gefitinib or erlotinib, so whether the efficacy of icotinib in lung adenocarcinoma is optimal remains to be further explored.

In conclusion, there is no difference in short-term clinical efficacy between icotinib and pemetrexed in the treatment of patients with lung adenocarcinoma. However, the median 
survival, progression-free survival and one-year survival of patients with lung adenocarcinoma treated with icotinib are higher than those treated with pemetrexed, and icotinib has significantly less toxic and side effects than pemetrexed, which is worthy of further research.

\section{Acknowledgements}

Not applicable.

\section{Funding}

No funding was received.

\section{Availability of data and materials}

The datasets used and/or analyzed during the present study are available from the corresponding author on reasonable request.

\section{Authors' contributions}

$\mathrm{XZ}$ and LW helped with analysis of the toxic and side effects. $\mathrm{XZ}, \mathrm{CG}$ and $\mathrm{YZ}$ were responsible for the collection and analysis of the experimental data. DH and LQ were responsible for the follow-up of the patients and drafted the manuscript. All the authors read and approved the final manuscript.

\section{Ethics approval and consent to participate}

The study was approved by the Ethics Committee of the Affiliated Hospital of Weifang Medical University (Weifang, China). Signed informed consents were obtained from the patients or the guardians.

\section{Patient consent for publication}

Not applicable.

\section{Competing interests}

The authors declare that they have no competing interests.

\section{References}

1. Black CN, Bot M, Scheffer PG, Cuijpers P and Penninx BW: Is depression associated with increased oxidative stress? A systematic review and meta-analysis. Psychoneuroendocrinology 51: 164-175, 2015.

2. National Center for Chronic Disease Prevention and Health Promotion (US) Office on Smoking and Health: The Health Consequences of Smoking-50 Years of Progress: A Report of the Surgeon General. Centers for Disease Control and Prevention (US), Atlanta, GA, 2014.

3. Thomas PA, Berbis J, Baste JM, Le Pimpec-Barthes F, Tronc F, Falcoz PE, Dahan M and Loundou A; EPITHOR group: Pneumonectomy for lung cancer: Contemporary national early morbidity and mortality outcomes. J Thorac Cardiovasc Surg 149: 73-82, 2015.

4. Zeng Y, Zhu J, Shen D, Qin H, Lei Z, Li W, Liu Z and Huang JA: MicroRNA-205 targets SMAD4 in non-small cell lung cancer and promotes lung cancer cell growth in vitro and in vivo. Oncotarget 8: 30817-30829, 2017.

5. Girard N, Corral J, Cortinovis D and Heigener DF: Second-line treatment selection in patients with non-small-cell lung cancer of adenocarcinoma histology: Findings from a European survey of treating physicians. Clin Lung Cancer 18: e89-e97, 2017.
6. Meaney CL, Zingone A, Brown D, Yu Y, Cao L and Ryan BM: Identification of serum inflammatory markers as classifiers of lung cancer mortality for stage I adenocarcinoma. Oncotarget 8: 40946-40957, 2017.

7. Wagland R, Brindle L, Ewings S, James E, Moore M, Rivas C, Esqueda AI and Corner J: Promoting help-seeking in response to symptoms amongst primary care patients at high risk of lung cancer: A mixed method study. PLoS One 11: e0165677, 2016.

8. Sha F, Zhuang S, Zhou L, Zhang L, Yang Y, Zhang S, Jiang Y, Qiu G, Chen C, Zheng J, et al: Biomarkers for cancer-related fatigue and adverse reactions to chemotherapy in lung cancer patients. Mol Clin Oncol 3: 163-166, 2015.

9. Shaw AT, Kim DW, Nakagawa K, Seto T, Crinó L, Ahn MJ, De Pas T, Besse B, Solomon BJ, Blackhall F, et al: Crizotinib versus chemotherapy in advanced ALK-positive lung cancer. N Engl J Med 368: 2385-2394, 2013.

10. Yao S, Zhi X, Wang R, Qian K, Hu M and Zhang Y: Retrospective study of adjuvant icotinib in postoperative lung cancer patients harboring epidermal growth factor receptor mutations. Thorac Cancer 7: 543-548, 2016.

11. Chen YT, Feng B and Chen LB: Update of research on drug resistance in small cell lung cancer chemotherapy. Asian Pac J Cancer Prev 13: 3577-3581, 2012

12. Liew SC: Folic acid and diseases - supplement it or not? Rev Assoc Med Bras 1992 62: 90-100, 2016.

13. Li B, Li MY, Sun LL, Wang J, Zheng YQ and Hao J: Impact of anticancer drugs price cut on physician's prescription choices on first-line chemotherapy regimens and health expenditure for advanced non-small cell lung cancer in China. J Thorac Dis 8: 2832-2842, 2016.

14. Mok TS,WuYL,AhnMJ,GarassinoMC,KimHR,RamalingamSS, Shepherd FA, He Y, Akamatsu H, Theelen WS, et al; AURA3 Investigators: Osimertinib or platinum-pemetrexed in EGFR T790M-positive lung cancer. N Engl J Med 376: 629-640, 2017.

15. de Kock I, Mirhosseini M, Lau F, Thai V, Downing M, Quan H, Lesperance M and Yang J: Conversion of Karnofsky Performance Status (KPS) and Eastern Cooperative Oncology Group Performance Status (ECOG) to Palliative Performance Scale (PPS), and the interchangeability of PPS and KPS in prognostic tools. J Palliat Care 29: 163-169, 2013.

16. Guenther LM, Rowe RG, Acharya PT, Swenson DW, Meyer SC, Clinton CM, Guo D, Sridharan M, London WB, Grier HE, et al: Response Evaluation Criteria in Solid Tumors (RECIST) following neoadjuvant chemotherapy in osteosarcoma. Pediatr Blood Cancer 65: 65, 2018.

17. Luo Y, Li J, Wang Y, Hao X and Qu F: Nimotuzumab combined with chemotherapy as second- or later-line in the treatment of advanced lung squamous cell carcinoma. Zhongguo Fei Ai Za Zhi 19: 665-669, 2016 (In Chinese).

18. Fritz I and Olsson H: Lung cancer in young women in southern Sweden: A descriptive study. Clin Respir J 12: 1565-1571, 2018.

19. Murphy RA, Mourtzakis M, Chu QS, Baracos VE, Reiman T and Mazurak VC: Supplementation with fish oil increases first-line chemotherapy efficacy in patients with advanced nonsmall cell lung cancer. Cancer 117: 3774-3780, 2011.

20. Kanesvaran R, Roy Chowdhury A and Krishna L: Practice pearls in the management of lung cancer in the elderly. J Geriatr Oncol 7: 362-367, 2016

21. Gutschner T, Hämmerle M, Eissmann M, Hsu J, Kim Y, Hung G, Revenko A, Arun G, Stentrup M, Gross M, et al: The noncoding RNA MALAT1 is a critical regulator of the metastasis phenotype of lung cancer cells. Cancer Res 73: 1180-1189, 2013.

22. Zhou L, He J, Xiong W, Liu Y, Xiang J, Yu Q, Liang M, Zhou X, Ding Z, Huang M, et al: Impact of whole brain radiation therapy on CSF penetration ability of Icotinib in EGFR-mutated non-small cell lung cancer patients with brain metastases: Results of phase I dose-escalation study. Lung Cancer 96: 93-100, 2016.

23. Song Z, Su H and Zhang Y: Patients with ROS1 rearrangement-positive non-small-cell lung cancer benefit from pemetrexed-based chemotherapy. Cancer Med 5: 2688-2693, 2016.

24. Scheinpflug K, Menzel C, Koch A, Kahl C and Achenbach HJ: Toxic epidermal necrolysis related to cisplatin and pemetrexed for metastatic non-small cell lung cancer. Onkologie 35: 600-603, 2012.

25. Ping W, Gao Y,Fan X,Li W, Deng Y and Fu X: MiR-181a contributes gefitinib resistance in non-small cell lung cancer cells by targeting GAS7. Biochem Biophys Res Commun 495: 2482-2489, 2018.

26. Ding T, Zhou F, Chen X, Zhang S, Liu Y, Sun H, Ren S, Li X, Zhao C, Wang H, et al: Continuation of gefitinib plus chemotherapy prolongs progression-free survival in advanced non-small cell lung cancer patients who get acquired resistance to gefitinib without T790M mutations. J Thorac Dis 9: 2923-2934, 2017. 
27. Liu Y, Zhang Y, Feng G, Niu Q, Xu S, Yan Y, Li S and Jing M: Comparison of effectiveness and adverse effects of gefitinib, erlotinib and icotinib among patients with non-small cell lung cancer: A network meta-analysis. Exp Ther Med 14: 4017-4032, 2017.

28. Lee JK, Hahn S, Kim DW, Suh KJ, Keam B, Kim TM, Lee SH and Heo DS: Epidermal growth factor receptor tyrosine kinase inhibitors vs conventional chemotherapy in non-small cell lung cancer harboring wild-type epidermal growth factor receptor: A meta-analysis. JAMA 311: 1430-1437, 2014.

29. Fennell DA, Gaudino G, O'Byrne KJ, Mutti L and van Meerbeeck J: Advances in the systemic therapy of malignant pleural mesothelioma. Nat Clin Pract Oncol 5: 136-147, 2008

30. Chen M, Cao H, Ji Y, Mao Y, Shen S and Li X: Association between the ALK Gene Status and the efficacy of first-line pemetrexed chemotherapy in patients with advanced lung adenocarcinoma. Zhongguo Fei Ai Za Zhi 20: 732-736, 2017 (In Chinese).
31. Shi Y, Zhang L, Liu X, Zhou C, Zhang L, Zhang S, Wang D, Li Q, Qin S, Hu C, et al: Icotinib versus gefitinib in previously treated advanced non-small-cell lung cancer (ICOGEN): A randomised, double-blind phase 3 non-inferiority trial. Lancet Oncol 14: 953-961, 2013.

(c) (i) $(9$ This work is licensed under a Creative Commons (c) Atro No Atribution-NonCommercial-NoDerivatives 4.0 International (CC BY-NC-ND 4.0) License. 